\section{ILUSIONES ÓPTICAS DEL ALMA: CONFLICTOS EN TORNO A LA REPRESENTACIÓN EN LA OBRA DE GÓMEZ DE AVELLANEDA (1860-1864)}

\author{
Mirta Suquet Martínez \\ Profesora Adjunta, College of Staten Island (CUNY) \\ mirtasuquet@gmail.com
}

\section{ILUSIONES ÓPTICAS DEL ALMA: CONFLICTS CONCERNING REPRESENTATION IN GÓMEZ DE AVELLANEDA'S WORK (1860-1864)}

Copyright: (c) 2014 CSIC. Este es un artículo de acceso abierto distribuido bajo los términos de la licencia Creative Commons Attribution-Non Commercial (by-nc) Spain 3.0.

. "Ilusiones ópticas del alma: conflictos en torno a representación en la obra de Gómez de Avellaneda (18601864)". Arbor, 190 (770): a190. doi: http://dx.doi.org/10.3989/ arbor.2014.770n6011

Recibido: 12 febrero 2014. Aceptado: 30 octubre 2014.

RESUMEN: Este artículo estudia textos de Gertrudis Gómez de Avellaneda escritos en su estancia en Cuba (1860-1864), con el objetivo de explicar las estrategias discursivas utilizadas por la autora para esquivar los reclamos nacionalistas de sus compatriotas. Frente a la política de la visión que da cuerpo a las demandas de objetividad de los nacionalistas, Avellaneda opta, en sus poemas de esta fecha, por un enfoque de la Isla desde la cautela y la distancia. En textos de crítica literaria y en la novela El artista barquero, Avellaneda defiende la reelaboración de la percepción a partir de una poética de las emociones que contrarreste el "positivismo" nacionalista.

PALABRAS CLAVE: Gertrudis Gómez de Avellaneda; visión; paisaje; percepción; nacionalismo; subjetividad; comunidad.
ABSTRACT: This article focuses on the texts Gertrudis Gómez de Avellaneda's wrote during her stay in Cuba (1860-1864), in order to clarify some discursive strategies used by the author to avoid the claims of her nationalist compatriots. Faced with the demands of objectivity of the nationalist authors, Gómez de Avellaneda chooses to avert her gaze and to approach the Island from caution and distance in her poems. Gómez de Avellaneda defends the re-working of perception in her literary criticism and her novel El artista barquero from a poetics of the emotions that resists the nationalist "positivism".

KEYWORDS: Gertrudis Gómez de Avellaneda; vision; landscape; perception; nationalism; subjectivity; community. 
A Susana Montero

\section{EL DESVÍO DE LA MIRADA Y LAS RETÓRICAS DE LA NO PERTENENCIA}

A finales de 1859, después de más de veinte años de residencia en España, Gertrudis Gómez de Avellaneda (GGA) viaja temporalmente a Cuba en compañía de su esposo, el coronel Domingo Verdugo. Como es sabido, el viaje se produce por recomendación médica -las anteriores estancias de la pareja en los balnearios pirenaicos en 1858 y 1859 parecen no mejorar la salud de Verdugo, quien había sufrido en abril de 1858 un atentado cuyas consecuencias finalmente le producirán la muerte, ya en tierras cubanas. La finalidad terapéutica del viaje a Cuba se conjugará con la responsabilidad política de Verdugo, designado teniente gobernador de Cárdenas a las órdenes del Capitán General de la Isla, en compañía del cual viajará la pareja a Cuba. Se trata de una estrategia sumamente ventajosa que propicia una opción terapéutica en apogeo -el turismo de salud asociado al termalismo y la climoterapia verifica un auge a partir de la segunda mitad del XIX en España sobre todo en zonas como Panticosa, Deva y los Altos Pirineos franceses, como da cuentas Antonio Espina y Capo en su Estudio de climoterapia é higiene..., 1901. El matrimonio se ve forzado a interrumpir su estancia en Bagneres de Bigorre, tal y como lo narra GGA en "Mi última excursión a los Pirineos" (1860) (Gómez de Avellaneda, 1860/1914, pp. 7-47), para embarcarse precipitadamente hacia la Isla, gracias a la mediación de la reina Isabel II. Estas circunstancias imprimen al retorno de Tula un carácter perentorio que trasciende la significación afectiva o identitaria del viaje: la Isla se avizora, ante todo, como promesa de salud y regeneración, tanto física, anímica e incluso poética, a la vez que deviene espacio de intervención y restauración política -para Verdugo-, y literaria -para Avellaneda ${ }^{1}$. No queda constancia de una producción creativa o memorialística de GGA que movilice imaginarios identitarios de apropiación o negociación en relación con las expectativas del retorno. Estos imaginarios (en torno a la recuperación de un sentido perdido en la estancia europea o de redescubrimiento de lo natal), sin embargo, serán puestos en boca de la poetisa en los poemas de bienvenida, como estrategia para dignificar la presencia de la escritora y revertir los móviles que condicionaron su viaje a la Isla².

En un poema de ocasión escrito en 1862 , pasado un tiempo de estancia en Cuba ("En el nacimiento de la querida primogénita de los Duques de la Torre"), se evidencian las esperanzas regeneradoras del via- je, simbolizadas a través del nacimiento de la hija del Capitán General, cuya gestación es asociada al poder benéfico del trópico. Se tematiza aquí un intercambio: Cuba concede los dones de fecundidad a los Duques de la Torre a cambio de un buen gobierno, del que también es parte integrante el coronel Verdugo. La composición, salpicada de ninfas y ondinas junto a topónimos taínos (Táyaba, Tínima, Macaguanigua, Sagua...), a la manera de un exotismo bucólico practicado como una especie de contextualización jovial, canta el despertar de la Isla con el nuevo mandato: "De un vírgen bosque á la sombra/ Que embalsamaban las brisas,/ Por sinsontes arrullado/ De Cuba el Genio dormía;/ Cuando de pronto resuena / Trueno de salva festiva, / Y la voz de la esperanza / -«iSacude el sueño!» Le grita: “¿No percibes por doquiera / Mi soplo, que blando anima/ Todas las almas cubanas, / De cuya esencia eres cifra?" (Gómez de Avellaneda, 1869, p. 347). En el romance cubano, los "númenes tutelares" de la Isla se confabulan para transferir a la recién nacida características de lo natural insular (el talle de las palmas, el aliento de las flores...). En este contexto neoclásico criollo, que insiste en la arcadización de la naturaleza a tono con la codificación estereotipada de lo tropical (exuberancia, magnificencia, prodigiosidad), pero traspolada al reino de lo fabuloso, Cuba es reproducida como escenario retorizado. El escenario de una puesta en escena fantástica muy diferente a otros romances cubanos de corte realista escritos de manera programática en la primera mitad del XIX (como los Romances cubanos de Domingo del Monte (1829-1833), y los de Ramón Velez Herrera, Ramón Palma, Milanés, entre otros). Avellaneda, que tiene pocos romances en su obra poética, y que tampoco suele escribir este tipo de fantasías paganas desvela aquí, en la elección de una forma marcada por los discursos pro-nacionalistas junto a contenidos elusivos que reducen a la Isla a una atemporalida sagrada, la dificultad de enunciar a Cuba.

Al final de este poema de celebración se hace patente un conflicto de enunciación que refleja la precariedad poética de Avellaneda; conflicto que no debe leerse como un agotamiento creativo, aunque así lo declare la autora. No olvidemos que poco antes de su viaje Avellaneda escribirá los memorables versos de "Paisaje Guipuzcoano" y durante su estancia en Cuba, "Las siete palabras y María al pie de la Cruz", entre otros poemas. Se trata, más bien, de la conciencia de un desencuentro con el lugar natal, los lenguajes poéticos locales y las expectativas de recepción, lo que se sintomatizará poéticamente en debilidad expresiva y amenaza de mutismo: “¿Qué puede darle á quien 
nace... / con sus himnos desmayados, / Una musa ya marchita? / ... Y cuando bendice un pueblo / Callar bien puede una lira!" (Gómez de Avellaneda, 1869, p. 353). Se hace patente aquí la oposición entre voz individual y expresión colectiva o social, no tematizada anteriormente en la poesía avellanedina: el bien decir (bendecir) del pueblo frente al callar bien de la poetisa. Curiosamente, en la revisón que hará del poema " $\mathrm{A}$ la poesía" (texto metapoético de su juventud, revisado en varias ocasiones) para la edición de sus poesías completas de 1869 dedicadas a Cuba, emerge la noción de "pueblo" como beneficiario directo de lo poético, como si su experiencia cubana hubiese determinado esta percepción. Si en la versión de 1850 se lee que la poesía "da al mortal en dulces ilusiones / de saber y virtud gratas lecciones" (Gómez de Avellaneda, 1850, p. 6), en la de 1869, después de su (des)encuentro con Cuba, y probablemente con una voluntad conciliadora, la autora rectifica la finalidad del acto poético: “Dándole al pueblo en bellas creaciones/ de saber y virtud santas lecciones" (Gómez de Avellaneda, 1869, p. 4).

Este desencuentro entre voz poética y comunidad será problematizado abiertamente en el prólogo a las Poesías de Luisa Pérez de Zambrana (1860/2005), escrito también en Cuba. Para Avellaneda, el poeta es un "heraldo peregrino y solitario" -acaso como ella misma, quien precisamente firmara como "La Peregrina" en sus textos de junventud. El poeta es, dice Tula, "la enérgica antítesis" de la sociedad: "[E]n el poeta individualmente examinado, no sólo no hallamos siempre la imagen o la expresión de la sociedad en que vive, sino que suele presentársenos como su enérgica antítesis; como heraldo peregrino y solitario de un orden de ideas más avanzado que su nación o que su siglo" (Gómez de Avellaneda, 1860/2005, p. 159). La oposición romántica entre la voz poética individualizada y el sentido común/comunitario muestra matices de verdadera hostilidad cuando GGA advierte en este texto que "en su calidad de hombre, el poeta está sujeto a la violencia de la corriente general", que termina por imponer al creador el espíritu de época (Gómez de Avellaneda, 1860/2005, p. 160). Conocedora de los mecanismos de legitimación literarios, la autora de Sab se apresura a vaticinar una recepción difícil para Pérez de Zambrana, dada la poesía intimista y deslocalizada de la cubana que la acercaría a la literatura contemporánea europea posición en la que GGA evidentemente se espejea: "bien podrá suceder que [el libro] no sea juzgado por muchos del número de aquellos característicos de la época y ni aún del pueblo en que aparece..." (Gómez de Avellaneda, 1860/2005, p. 166).
El recurso al silencio poético que comentamos (“Callar bien puede una lira!") evidencia una toma de precaución que recorre las obras sobre tema cubano escritas y publicadas por Avellaneda durante la estancia en Cuba. La cautela de la escritora se expresa a través del motivo del agotamiento creativo, o de su incapacidad para expresar las nuevas emociones y vivencias del reencuentro, así como de la repetición de lugares comunes (sobre todo, paisajísticos), de estrategias de delegación enunciativa (como el uso de la prosopopeya) e, incluso, de incursiones en formas poéticas calificadas por la propia autora como "caprichosas", que le permiten crear atmósferas de fabulación atemporales y escapar, de esta forma, de una referencialidad inmediata ${ }^{3}$. Estas son algunas de las estrategias que le posibilitan no recurrir precisamente al silencio ante los conflictos entre una poética personal deslocalizada, que a la altura de estos años ya está consolidada, y un deber ser poético marcado por retóricas localistas de apropiación y producción de lo nacional estabilizadas desde las décadas 30-40 en el seno del círculo de Domingo del Monte. Difícilmente la autorreferencialidad del yo poético avellanedino podía participar de las lógicas de suplantación de voces que propugnan los letrados criollos por estas fechas (la del montero, del veguero, del guajiro/a o del cacique indiano...), de la poesía descriptiva de la naturaleza (a la manera de los poemas de Francisco Iturrondo o de Ramón Vélez Herrera), así como de la fabulación de comunidades étnicas o regionales de la poesía criollista y siboneyista del segundo romanticismo cubano (José Fornaris, Joaquín Lorenzo Luaces, Juan Cristóbal Nápoles Fajardo). GGA, ajena a estas políticas y pedagogías de la visión centradas en imaginar y re-producir lo cubano, explica las tendencias objetivistas locales a través de una conexión entre la "exuberante riqueza" de la Isla y la propensión de los escritores a lo material (en detrimento de lo espiritual), algo que termina por "impregna[r] la atmósfera común de cierto positivismo contagioso" (Gómez de Avellaneda, 1860/2005, p. 162).

La inadecuación entre el registro poético de GGA y una estética supuestamente más acorde a las demandas del espacio insular (juvenil, festiva, colorida...), ya se había explicitado en su respuesta a un poema de Franchi Alfaro en el que ésta poetisa instaba a GGA a regresar a la patria y a escribir en y de ella. La poeta declina la petición alegando la imposibilidad de aclimatar su lira a la "agreste armonía" natal, y aprovecha para llamar "sirena" a la joven poetisa (Gómez de Avellaneda, 1869, p. 263), aún cuando ella misma se había opuesto a que la llamasen de esta manera (véase el poema "Romance", Gómez de Avellaneda, 1869, 
p. 207). Tras la negativa de Avellaneda amparada en su duelo lo que se lee, en definitiva, es su rechazo a comulgar con los lenguajes criollistas. Hay en GGA una resistencia a naturalizar (y nativizar) su poesía, en tanto esto supone, básicamente, una reducción al exotismo local y a los estándares de la escritura femenina, que convierte a la naturaleza en unos de sus temas preferentes, dos paradigmas de los que se distancia la poesía avellanedina: “¿Por qué á la indiana pradera / Mansión de luz y de flores/ Anhelas que mi arpa austera / Vaya á exhalar la postrera / Vibración de mis dolores? [...] No esperes que la voz mía / En ese plácido ambiente, / Do exhalas tu poesía, / Lance en agreste armonía / Quejas de un alma doliente" (Gómez de Avellaneda, 1869, pp. 263-264).

El rechazo a los modelos poéticos locales se verifica, además, a través de un desvío de la atención hacia proyectos que no tributan directamente a los problemas nacionalistas, como la revista quincenal El Álbum de lo bueno y lo bello (1860), o la escritura de El artista barquero (1861), novela en la que coloca a sus personajes cubanos en la Francia de Luis XV. Este desvío se ejemplifica de manera literal, como una política de la mirada esquiva en "A la vista del Niágara", poema que cierra el ciclo del reencuentro con la patria y con sus lugares comunes. El sujeto lírico desvía la mirada de las cataratas y en vez de proyectar el paisaje cubano como alucinación patriótica, a semejanza de José María Heredia, detiene su vista en el puente tubular sobre el río San Lorenzo, símbolo del "modelo liberal" norteamericano y de la pujanza de la modernidad cosmopolita. De esta forma, GGA desaprovecha una ocasión idónea de afiliarse al canon lírico-patriótico de la Isla, y apuesta por otra imagen, des-naturalizada y transnacional, que escapa de la esencialidad paisajística y de la autorrferencialidad identitaria (Pratt, 2003, pp. 43-44). La voluntad de GGA de no restringirse a los imaginarios nacionalistas la acercaría, en definitiva, a otras intelectuales latinoamericanas cuyos textos tampoco se circunscriben "a la homología nación-cultura" (Pratt, 1993, p. 55). Como bien ha explicado Mary Louise Pratt, las intelectuales latinoamericanas del XIX han tendido a enrumbar su trabajo hacia prácticas "de mediación transnacional" (expresadas en términos mundiales o hemisféricos), toda vez que se han encontrado sistemáticamente excluidas de los cauces y lenguajes locales restringidos a la figura del "letrado" -masculino y pro-independentista (Pratt, 1993, p. 55).

No es menos cierto que esta escritura evasiva, desde el punto de vista de lo cubano, está fuertemente condicionada por el compromiso de la escritora con la nueva administración del gobierno. Por esta razón se le imagina, a priori, maniatada, silenciada: "la Musa como sierva infortunada/ solloza al poste del verdugo atada" (Gómez de Avellaneda, 1860/1914, p. 509), avisa Fornaris veladamente, haciendo referencia al apellido del esposo de Avellaneda, en el texto que leyera en el teatro Tacón para homenajear a la poetisa ${ }^{4}$. Avellaneda, en cambio, de acuerdo a lo que venía publicando anteriormente en la Península, dará a conocer el extenso relato de su viaje a los Pirineos franceses (que publicará el Diario de la Marina en dieciocho entregas en forma de folletín entre junio y julio de 1860), reeditará algunas tradiciones y leyendas europeas en su Álbum cubano de lo bueno y lo bello, además de escribir los artículos en torno a la condición femenina también publicados en su revista. También publicará poemas variados, algunos de motivos europeos o religiosos, como "Romance escrito en una hora de desvelo en las playas de San Sebastián", o "Las Siete Palabras y María al pie de la Cruz", que aparecen en el Álbum, y terminará su última novela, El artista barquero, contextualizada en la Francia monárquica a la que trufará de motivos cubanos. Este recuento muestra una GGA deseosa de publicar en la isla, de contar su experiencia europea y de defender, en definitiva, la autonomía del arte.

Es sintomático que la autora de la "Carta a Eloísa" (1838, publicada en 1914 por Figarola Caneda) -texto íntimo en el que había narrado sus primeras impresiones europeas-, y alguien que hace del motivo del viaje un tema recurrente en sus obras (lanes, 1997), no escribiese a propósito de su estancia en Cuba, un relato como la ya mencionada obra de la condesa de Merlin, a pesar de haber prologado la edición en castellano de Viaje a La Habana. Esto se revela especialmente significativo si tenemos en cuenta que en los años anteriores a su viaje a Cuba se había dado a conocer como escritora de viajes (en "Viaje a las provincias vascongadas", publicado en el periódico El Estado en 1857, y en "Mi última excursión a los Pirineos", publicado en el Diario de la Marina en 1860). En estos relatos, trufados de detalles, cuadros pintorescos y leyendas locales, GGA ofrecerá la imagen de una curiosa escritora en constante retroalimentación con los parajes visitados, siempre con un cuadernillo a la mano dispuesta a anotar las singularidades de cada sitio (Ezama Gil, 2011). Sorprende, además, el desinterés de la autora por las leyendas o relatos orales cubanos, a excepción de la leyenda "El aura blanca" (incluida en Obras Literarias, 1871), sobre todo porque GGA se había mostrado atenta re-elaboradora de historias locales desde que escribiera "La velada del helecho" en 1849, e incluso antes, al registrar la le- 
yenda del cacique Camagüey en Sab. En los dos relatos de viaje ya mencionados ("Viaje a las provincias..." y "Mi última..."), escritos los años antes de su viaje a la isla, GGA intercalará una series de leyendas que luego publicará como relatos autónomos, lo cual demuestra el interés de la autora en recoger de primera mano anécdotas o leyendas locales de Europa ${ }^{5}$.

Podríamos fabular que Tula, que se había enfrentado a su aventura europea en 1836 en calidad de peregrina -como precisamente se autocalificará en los comienzos de su vida literaria en España ${ }^{6}$-, regresará a la isla en 1859 con otra actitud vital menos trascendente, probablemente más cercana a la sensibilidad del turista (o del paseante), cuya emergencia comienza a verificarse en Europa hacia la segunda mitad del XIX. Ya GGA había recreado esta identidad transitoria justo antes de su peripecia cubana, en el relato de viaje mencionado anteriormente, "Mi última excursión a los Pirineos". En este texto, que evidencia el carácter cosmopolita de la escritora, ésta no duda en presentarse a sus compatriotas como una atrevida e infatigable "tourista" (la variante castellana no será registrada en el Diccionario de la Real Academia Española hasta 1914), que en compañía de excursionistas de diversos orígenes formará una comunidad fluida y trasnacional: "nosotros, touristas, vagabundos que sólo buscábamos impresiones variadas" (Gómez de Avellaneda, 1860/1914, p. 23).

Es interesante traer a colación los argumentos de Zygmunt Bauman a propósito de la figura del peregrino y los sucesores de ésta -el turista, el vagabundo y el paseante o flâneur-, en relación con las diferentes perspectivas de conceptualización del lugar y la identidad en la Modernidad. En la idea moderna y secular de la vida como peregrinación, especula Bauman, el mundo y el peregrino "adquieren sentido juntos $y$ cada uno a través del otro" (Bauman, 2003, p. 46, énfasis del autor). Se trata de una semiotización recíproca que apunta hacia la formación continua de la individualidad: la vida como camino de aprendizaje, como proyecto y meta aplazable, pero teleológicamente impulsada hacia la utopía del sacrificio-recompensa. Si la voluntad de peregrinación remite, en los inicios intelectuales GGA, al viaje transatlántico y a la pujanza con que enfrenta su periplo por las letras peninsulares con una pretensión fundacional -de hacer el camino, de marcar el territorio-, el viaje de retorno a la isla le confirmará su no pertenencia al lugar, a la vez que su renuncia a pertenecer en tanto figura deslocalizada, situada en un entre lugar problemático que la desencuentra con las dinámicas de subjetivación empren- didas por sus compatriotas criollos. Como el turista, podrá jugar al como si, a la empatía transitoria, pero no puede llegar a suspender su ajenidad, a naturalizarse: el turista, advierte Bauman, "está en todos los lugares donde va, pero en ninguna parte es del lugar" (Bauman, 2003, p. 59).

De esta forma, la poetización de la isla en el texto de salutación "La vuelta a la patria" recrea, por ejemplo, una escenografía no domesticada o familiar que involucra un enfoque distanciado, de no apropiación o identificación. La poetisa quiere que su voz recorra toda la Isla y para ello, delega esta posibilidad en el viento:

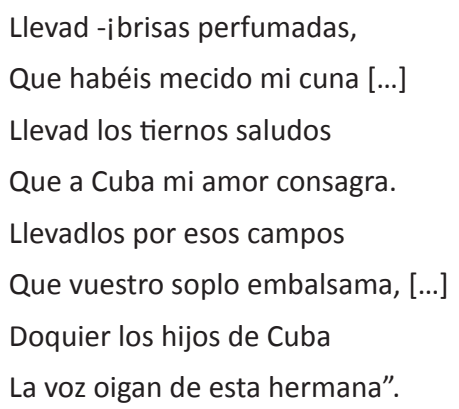

Llevad -ibrisas perfumadas,

Que habéis mecido mi cuna [...]

Llevad los tiernos saludos

Que a Cuba mi amor consagra.

Llevadlos por esos campos

Que vuestro soplo embalsama, [...]

Doquier los hijos de Cuba

La voz oigan de esta hermana".

(Gómez de Avellaneda, 1869, pp. 334-335).

Si cuando Tula parte de la Isla en 1836, la patria que se evoca inmediatamente es el ámbito afectivo más cercano, local (piénsese, por ejemplo en las referencias a [Santiago de] Cuba en la "Carta a Eloísa", que en modo alguno pueden ser leídas como alusiones a Cuba), en este poema se imagina la patria en una dimensión más extensa, acorde con las figuraciones del pensamiento geopolítico nacionalista. Pero esta patria imaginada como extensión es, por ello mismo, un topos (y tópico) menos intenso -emocional y referencialmente hablando-; más aún cuando ni siquiera ha sido experienciada como tal ${ }^{7}$. Por eso utiliza la figura del viento para expresar esa calidad extensiva que no puede (ni sabe cómo) aprehender. El viaje de retorno a lo natal de la Condesa de Merlin, compatriota exiliada con la que Avellaneda se identifica públicamente en 1844 (en el "Prólogo" a Viaje a la Habana), resulta ser un regreso a las posesiones de infancia que serán confrontadas en sus escritos memorísticos (casa, familia, criados); en cambio, Avellaneda retorna a un espacio no marcado ni singularizado (La Habana, y por extensión, la Isla), salvo por la generalidad de haberlo evocado durante veinte años como lo natal. Esta im-propiedad y falta de re-conocimiento se evidenciará en sus poemas.

En el poema que comentamos, más que distinguir y singularizar el paisaje, sobresale el gesto de despropiación; más que reencontrar-se, el sujeto se disemina: "En cuyo inmenso horizonte / Quiero perder mis mi- 
radas" (Gómez de Avellaneda, 1869, p. 335), desea el sujeto lírico. Este enfoque contrasta con otras perspectivas paradigmáticas de reencuentro con lo natal que son menos elusivas, o si se quiere, más de tipo testimonial, como la visión localizada de José María Heredia en el famoso "Himno del desterrado" (1825). En este poema, la isla se divisa desde sus costas y se patentiza la emoción inmediata del reconocimiento, también relatada por la condesa de Merlin cuando detalla, en su tránsito por la costa cubana, los puntos significativos de la orografía y arquitectura insular. La "vista de lince" de la condesa (de la que se mofa Tanco Bosmeniel en su Refutación al folleto intitulado Viaje a la Habana [Bosmeniel, 1844, p. 5]), que pone en evidencia el deseo de ver y nombrar de la recién llegada es similar a la mirada ansiosa de Heredia, quien identifica en la distancia el paisaje familiar -el Pan de Matanzas-, e imagina la filiación comunitaria a partir de lo geográfico ${ }^{8}$.

En "La vuelta a la patria", como en otros textos de Tula escritos en la Península, la isla es recuperada en una dimensión sonora sublimada (como advertirá Sarduy en un bello texto de 1981). Dice GGA: "Cual vago concento de hadas-/ la misteriosa armonía / De árboles, pájaros, aguas,/ Que en soledades secretas/Con ignotas concordancias, / Susurran, trinan, murmuran, / Entre el silencio y la calma" (Gómez de Avellaneda, 1869, p. 334). Frente a este concierto sugestivo la mirada objetivadora se clausura y ningún "ruido" viene a contextualizar el paisaje, como en el mencionado texto herediano ${ }^{9}$. La contextualización es de tipo nominal; se mapea una geografía unitaria en cuyos límites se circunscribe el alcance poético: "Desde la punta Maisí / Hasta la orilla del Mantua; / Desde el Pico de Tarquino/ A las costas de Guanaja" (Gómez de Avellaneda, 1869, p. 335), dice Tula a la manera de los discursos cartográficos. Algo tan específico como un topónimo (el punto orográfico más alto de la isla, nombrado por GGA como "Tarquino"), subraya, sin embargo, la condición exo/tópica de la autora. Ello es así si tenemos en cuenta que en la Geografía física y política de la isla de Cuba escrita por Felipe Poey para la enseñanza pública, que vio la luz en 19 ediciones corregidas continuamente entre los años 1836-1860, se estabiliza el término "Turquino", con el que será conocido hasta el presente esta montaña, a partir de una etimología asociativa que rectifica la motivación cultista del nombre "Tarquino"10.

En el poema que hemos venido comentando ("La vuelta a la patria"), GGA establece la dificultad de expresar su relación afectiva con Cuba, a pesar de que el texto está impregnado de una retórica patriótica que disimula la posición conflictiva de la hablante. Amparada en la brecha entre el lenguaje y las emociones, la autora apela a la inconmensurabilidad de su sentimiento y a la imposibilidad de articular lo inefable: "Si afectos profundos / traducir pueden palabras / Por los ámbitos queridos / llevad, ibrisas perfumadas /... Llevad los tiernos saludos / que a Cuba mi amor consagra" (Gómez de Avellaneda, 1869, p. 333). Estos saludos se quedan sin verbalizar; el lenguaje no verbal -el suspiro- se revela más auténtico que las palabras ("llevadlos férvidos, puros / cual de mi seno se exhalan" [Gómez de Avellaneda, 1869, p. 335]): de cualquier forma, se trata de una enunciación vacía, de una falta de palabras: "Aunque del labio el acento / a formularlos no alcanza... Pero iah! Decidles que en vano / Sus ecos le pido a mi arpa; / pues sólo del corazón / Los gritos de amor se arrancan" (Gómez de Avellaneda, 1869, pp. 335).

Como es sabido, el tópico de la ineficiencia del lenguaje adquirió peso fundamental en las retóricas del Romanticismo, sobre todo a partir de la crisis de la racionalidad que emerge con los nuevos repertorios emocionales. Esta crisis del lenguaje será cada vez más sintomática de la angustia finisecular moderna, reflejada especialmente por Hugo von Hofmannsthal (1874-1929) en su "Carta de lord Chandos" (1902). Pero en el caso de los poemas de GGA que comentamos, las emociones inexpresables aluden más bien a un registro no conocido o compartido; a su vez, ponen en evidencia la cautela de la escritora y sus reticencias a la hora de expresar una experiencia que pueda delatar su percepción extraña, distanciada o de intrusa.

En los pocos momentos en que enfoca de manera directa los temas cubanos, lo hace como experta ventrílocua -a la manera de los discursos locales-, pero en tales casos se vale del artilugio de la ineficacia del lenguaje o de su propia incapacidad -al remitir a su lira rota o al retratarse como musa marchita- para suspender o precarizar el discurso. Esta limitación de expresión se verifica en el poema improvisado en el Acto de Coronación en el Liceo en La Habana, el 27 de enero de 1860. En él se lee: "Romped, romped mi lira, que impotente / Nunca alcanzar sabrá de la armonía / Tonos que os den en vibración valiente / La voz que al labio el corazon envia" (Gómez de Avellaneda, 1869, p. 341). En el poema GGA termina afirmando nuevamente el valor testimonial de las expresiones corporales como prueba de la veracidad o autenticidad de su afecto, por encima de las palabras de la poesía: "Mas joh! Dejad que os muestre su energía / Con lágrimas de amor y no con cantos!" (Gómez de Avellaneda, 1869, p. 341). 
En "A las cubanas", el otro poema escrito a su llegada a Cuba como salutación cívica, tampoco se compromete a recomponer su lira para testimoniar el reencuentro: el "quizás" enfatiza la incertidumbre ("Quizás en este ambiente de poesía / Para cantaros cobre nueva armonía", 1869, p. 337). Se ratifica la limitación de la expresión poética en versos que, por otra parte, establecen la desemejanza del hablante lírico con respecto a sus coterráneas, a pesar de la voluntad de comunión con que comienza el poema ("respiro entre vosotras", 1869, p. 337). En el hipérbaton de los versos centrales del poema emerge un sujeto masculino, ya antes diferenciado de la femineidad de "las cubanas" (identificadas con "blando aliento", sonrisas, dulzura, rizos, joyas, mientras que el hablante lírico se identifica con "crudos enojos", alma herida, "pecho herido", pensamiento: "El que ántes exhalaba ferviente canto, / Raudales apagaron de acerbo llanto;/ Y hoy cuando vibra, / De postración gemidos al aire libra" (Gómez de Avellaneda, 1869, p. 337). Esta gravedad justifica las reservas enunciativas de la voz poética, pero sobre todo se hace des-semejante al "blando aliento" de sus coterráneas.

Si tenemos en cuenta que las retóricas paisajísticas que articulará GGA en estos poemas resultan similares a las utilizadas en textos anteriores publicados en la distancia, sin que se perciba una re-elaboración de los espacios y los estereotipos culturales, podríamos confirmar la voluntad de la autora de reproducir el lugar comunitario como lugar común (tópico poético), y el paisaje natal como argumento retorizado. Colocarse más allá de esta lógica discursiva elevada al rango de identidad proto-nacional implicaría, en su caso, el silencio.

\section{ILUSIONES ÓPTICAS DEL ALMA: EL PAISAJE IMAGI- NADO EN LA DISTANCIA}

En el ya citado prólogo a los poemas de Pérez de Zambrana, GGA apela a una literatura "actual" europea, universalista y cosmopolita ("en la que la ciudad parece bosquejarse", dice quien parece ser temprana lectora de la poesía moderna francesa), frente a la que las modalidades nacionalistas devienen literaturas de infancia o juventud: "La literatura ecléctica que predomina en nuestros días tiende a formarse en condiciones que no la estrechen en el círculo de un pueblo o de una época [...] como si aspirase a sintetizar no ya una nación ni un tiempo, sino a la humanidad misma. Este carácter de la literatura actual [...] está en perfecta consonancia con el espíritu moderno, evidentemente nivelador y universal" (Gómez de Avellaneda, 1860/2005, pp. 165-166).
Como hemos advertido, GGA toma distancia de la vocación objetivista de aquellos poetas cubanos que, centrados en la naturaleza insular, "no aciertan más que a expresar sensaciones" (Gómez de Avellaneda, $1860 / 2005$, p. 165). Legitima, por el contrario, una estética que re-elabore las impresiones inmediatas y las convierta en emociones o sentimientos (como el "espiritualismo melancólico" de Pérez de Zambrana). Ya en la elección de La Fille du roi René de Gustave Lemoine para su adaptación a la escena española, GGA había mostrado un interés en los conflictos en torno a la visión, probablemente como defensa de un sensualismo que reacciona frente al auge del positivismo. Vale la pena recordar, sin embargo, que será precisamente esta obra, La hija del Rey René (pieza en un acto estrenada antes en Madrid en 1855), la que se presentará en el acto oficial de homenaje a la escritora celebrado en el Teatro Tacón el 17 de enero de 1860. Si tenemos en cuenta que se trata de una obra menor y, por demás, no de asunto original (basada en la obra homónima de Henrik Hertz, traducida al francés por Limoine), podemos inferir que su elección no debe haber sido fortuita. En este caso, entendemos el argumento de $L a$ hija del Rey René como el sucedáneo dramatizado de los reclamos públicos dirigidos hacia GGA a su llegada a Cuba: a la escritora se le demandaba justamente la recuperación de la visión; una obra menos elusiva, más directa, que inscribiera más claramente la referencialidad del paisaje cubano. La obra, además, puede haber tenido una relectura política no menos importante si se identifica el conflicto de la hija del Rey con la condición colonial de Cuba ${ }^{11}$. La obra, sin embargo, le ofrecía a GGA la posibilidad poética de recrear un mundo hecho a la medida de sensaciones subjetivas no mediadas por lo visual (sino por olores, texturas y sonidos) y de emociones basadas en primeras experiencias sensibles.

Edmond Cros (2010) remarca el impacto que las investigaciones de óptica fisiológica tendrán en las teorías de la representación artística en Europa después de la segunda mitad del XIX, sobre todo para el simbolismo y para la génesis de conceptos como la sinestesia, hasta llegar a las conceptualizaciones de las vanguardias y el arte abstracto. El estudioso francés se detiene en las teorías de la percepción de Von Helmholtz y de su discípulo Augusto Laugel, quienes distinguieron dos procesos complementarios de integración óptica del paisaje: la impresión, obra del nervio óptico, y las emociones, resultado de la elaboración cerebral. Esta re-definición de la percepción, concluye Cros, está en la génesis de la autonomía y arbitrariedad del signo lingüístico (Ferdinand de Saussure), en el psicoanálisis y en las teorías del arte del siglo XX. 
Si repasamos con cuidado la última novela de GGA (El artista barquero [1861]) encontraremos algunas correlaciones intersensoriales a la manera de sinestesias -que la autora, en cambio, se precipita a disculpar como "hipérboles"-, las cuales crean la ilusión perceptiva que sustenta la tesis de la novela, esto es, que la imagen artística puede suplir el referente real, en este caso el paisaje natal, perdido en la experiencia de la emigración -o al menos, esa imagen puede aquietar el deseo ${ }^{12}$. Precisamente los conflictos en torno a la percepción ya habían sido poetizados por GGA a propósito de la pretendida sublimidad del paisaje americano. En "El viajero americano", la autora contrapone dos perspectivas irreconciliables de focalización del paisaje, derivadas, lógicamente, del carácter situado del espectador: la mirada desde la lejanía que funda la utopía y la mirada que, en el lugar, destruye el ensueño utópico. El paisaje en la lejanía -paisaje imaginado desde un afuera o exo-topía que puede remitir al exilio-, es siempre un espejismo, una ficción aquietadora. En el lugar ocurre la cancelación del paraje mental de reconciliación originaria, el sueño de retorno a un tiempo-espacio sagrado, inmutable (matria/patria). Así, en la distancia, se idealizan "suspendidos en los aires/ Jardines bellos de abundantes galas": un paisaje encantado, sostenido por silfos de movibles alas... Cuando el viajero "vuela veloz y la distancia salva" descubre que los jardines paradisíacos resultan ser, en realidad, no más que "ilusiones ópticas" ("i[un] gran desierto que tapizan lavas!”, 1869, p. 214) ${ }^{13}$.

La percepción visual no es fiable; el individuo, tanto como el paisaje, no pueden ser integrados o definidos a plenitud, toda vez que se desdoblan en la perspectiva interior/ exterior que define la subjetividad moderna ${ }^{14}$. En la belleza utópica aflora el unheimlich que amenaza secretamente la estabilidad de la visión (algo que trabajará en sus leyendas, como en La ondina del Lago Azul). GGA parece insinuar en este poema, además, que el telos del viaje, como el de la escritura, no es la conquista del edén, la llegada a un lugar prometido o ensoñado, sino el descubrimiento de una verdad en ruinas que subyace tras la visión mitificada (como el paisaje natal recreado en El artista barquero: la heredad arruinada que sólo puede reificarse a través de la ficción artística). Para Pratt, esta imagen amenazadora -el desierto de lavas-, tendría una referencia contextual más directa si es leída como una metáfora "post-independentista de esperanzas disecadas y sueños estancados", utilizada por Avellaneda para "desmistificar la retórica cívica de sus inmediatos antecesores [Heredia, Bolívar]" (Pratt, 1993, p. 59). En esta línea de indagación, podríamos afirmar que los reiterados incendios, destrucciones y reconstrucciones que se suceden en las novelas sobre tema cubano y latinoamericano de Avellaneda (Sab, Guatimozín, El artista), son metáforas de los sustratos de una historia colonial cuyo punto de partida y llegada es la ruina ${ }^{15}$.

Una obra que plantea, precisamente, los vínculos entre percepción y paisaje es la novela El artista barquero. En ella se muestra el impulso humano por sacralizar los lugares afectivos -patria, hogar-, esto es, por extraerlos de un continuum temporal o histórico y convertirlos en piezas sublimadas por el recuerdo. En esta reflexión se inserta la pregunta sobre la funcionalidad del arte, concomitante con este ejercicio de sublimación memorialística. Aún residiendo en Cuba en el momento de la escritura de El artista barquero, Avellaneda se resiste a abandonar los contextos europeos, y por esta razón se sitúa desde una perspectiva transatlántica para enfocar la isla, como si sólo a través de esta mirada exotópica -consolidada en más de veinte años de vivir fuera de Cuba- pudiera representar con autenticidad su relación con la patria perdida. En El artista..., la autora resalta en definitiva la imposibilidad de recuperar la Isla como espacio físico concreto.

En la novela GGA se sitúa a finales del siglo XVIII para narrar la historia de una familia cubana emigrada a Francia, además de otros conflictos propios de la emergencia del artista moderno que no podemos abordar en este ensayo ${ }^{16}$. La nostalgia por el suelo patrio provocará el intempestivo retorno de la familia expatriada a Cuba, pero al regreso encontrarán destruido el sitio evocado en la distancia. El que fuera escenario de fundación y bienestar familiar -el templete diseñado por el abuelo, en cuyo frontis se leía la inscripción "Recuerdo eterno"- ha quedado convertido en ruinas por la intervención del nuevo dueño. Con esta ruina arquitectónica GGA parece evocar la decadencia espiritual de Cuba, presa de un "positivismo contagioso", como diría en el prólogo a las Poesías de Pérez de Zambrana (Gómez de Avellaneda, 1860/2005, p. 162):

Nuestros deudos, usando de los poderes que les dejó mi padre -casi sin conciencia de ello- lo habían vendido todo [...]. El nuevo dueño del cafetal, hombre positivista y vulgar para quien nada era bello sino lo materialmente útil, juzgó que estaría la colina mucho mejor empleada siendo el asilo de un enorme criadero de palomas -hecho con el maderámen del templete. (Gómez de Avellaneda, 1861, pp. 48-49).

El templete reducido a maderámen se convierte en fragmento de un tiempo perdido que desvela la nos- 
talgia de GGA por modelos aristocráticos fundacionales, sustituidos con la emergencia de valores burgueses. En tales circunstancias, el paisaje, sometido a los imperativos utilitarios, sólo puede recuperar su función simbólica -religadora de lo familiar/social- y estética por medio del arte. A partir de esta decepción, el padre de familia (Mr. Caillard) se verá poseído por la "monomanía" de sustituir el objeto perdido por un artefacto artístico:

En la imposibilidad de recobrar, tal cual lo necesita, el sitio consagrado por todas las alegrías de su vida, se ha apoderado de él atormentador afán de verlo reproducido por el arte. Á poco de su vuelta á Francia encargó la pintura exacta de aquel paisage á cuantos artistas hay en la Habana: pero, aunque algunos de ellos habían visto el original muchas veces, ninguno alcanzó á imitarlo de un modo que dejára satisfechas las exigencias del viudo inconsolable (Gómez de Avellaneda, 1861, p. 49).

Con El artista GGA ratifica el valor del arte para reedificar las ruinas e incluso, para suplantar el paisaje emocional que es la patria. La novela da cuenta, además, de una cadena de suplantaciones en la que lo original es más bien un deseo que impulsa la reproducción. En tal sentido, esta obra de GGA, descuidada inmerecidamente por la crítica, es una representación compleja de las relaciones intermediales entre lenguajes artísticos: el paisaje verbalizado -las remembranzas de la familia exiliada- será trasvasado a una representación pictórica que será a su vez descrita en la novela, o sea, nuevamente traducida a palabras. A su vez, la escritura de la novela es en sí misma el acto de recuperación de la patria mediado por la fabulación narrativa. Una patria que no son los restos del presente, sino el recuerdo idealizado del pasado y estetizado por el arte. De manera sintomática, se nos recalca que el origen perdido -si es que existe este origen y no es ya un producto de la ficción del emigrado- no puede ser recuperado por los artistas locales, demasiado atados a un referente concreto, para ellos despojado de una significación añadida; o, acaso, demasiado apegados a la recompensa prometida (en el caso de la novela, por Mr. Caillard).

Otra relación con el paisaje será la que logre llenar la falta original; aquella impulsada por la pasión con que serán narrados los recuerdos del pasado por Josefina, la cubana hija de Mr. Caillard. Descrita con el "fuego del sentimiento que prestaba vida á sus palabras", la Isla se presentará vívida a los ojos del pintor marsellés Hubert Robert, pretendiente de Josefina. ("Mientras ella hablaba el artista hacía volar el lápiz" (Gómez de Avellaneda, 1861, p. 198). De esta forma, puede explicarse que el pintor que logra finalmente materializar el deseo del emigrado será aquel que no ha visto la Isla "ni aun en pintura" (Gómez de Avellaneda, 1861, p. 151); quien la reinventa a partir de sus propios modelos europeos -la bahía de Marsella o los Jardines de Versalles-, pero que, en cambio, será capaz de apropiarse de las experiencias ajenas y de traducir en imágenes físicas la ficción verbalizada. En ello radica el genio artístico. En El artista... GGA tiene la osadía de imaginar una dislocación extrema entre el creador y el contexto, y entre el paisaje y la representación. Y lo que es más arriesgado, no descalifica el resultado artístico como impostura o simulacro, sino que lo valida como auténtico, en tanto veraz y efectivo.

Esta es la única novela de Avellaneda que tiene un final feliz: la familia emigrada no regresa a la Isla, sino que se enraíza definitivamente en Europa. La patria física se recupera a través de su mímesis (la pintura), y una vez sublimada, desaparece la monomanía nostálgica del expatriado. El lugar emocional, en cambio, se construye allí donde la familia se agrupa.
1 En su poema "A las cubanas" se lee el ansia regenerativa no solo física, sino también poética, cifrada en el clima tropical: "Quizás en este ambiente de poesía/ Para cantaros cobre nueva armonía,/ Y al sol de Cuba -Vuestro amor bendiciendo- su canto suba./ Sí; porque en esta zona de resplandores/... el pecho herido/ Se siente por su aroma fortalecido" (Gómez de Avellaneda, 1869, p. 337).
2 Esto se verifica en los poemas compilados en el volumen Misceláneas de las obras completas de 1914, como el himno de coronación escrito por José Ramón de Betancourt para el acto celebrado en el Liceo de La Habana (Gómez de Avellaneda, 1860/1914, pp. 506-508)

3 En "Serenata de Cuba. (Fantasía)", publicada en la edición de las obras completas de 1869, la autora hace una llamada para aclarar que "[e]sta caprichosa composición, como algunas otras de las del tercer cuaderno, inédito, fueron escritas en la Habana..." (Gómez de Avellaneda, 1869, pp. 360). En la "fantasía”, numerosos elementos naturales son convocados a hablar, gracias al recurso de la prosopopeya; un concierto de voces que sustituyen a la de la "poeta", devenida simple amanuense. 
4 Escoto cita un soneto satírico que recorrió la Isla, presumiblemente escrito por José Fornaris, en el que se hace evidente el juego con el apellido del esposo de Gertrudis: "Hoy vuelve a Cuba, pero a Dios le plugo/ que la ingrata torcaz camagueyana/ tornara esclava, en brazos de un verdugo" (Escoto, 1911, p. 10). Para un análisis de los discursos nacionalistas e histórico-literarios cubanos con respecto a la Avellaneda, véase Alzate Cadavid (2001).

5 Las dos leyendas intercaladas en "Viaje a las provincias vacongadas" serán publicadas en Cuba en el Álbum cubano de lo bueno y lo bello con los títulos "La flor del ángel (tradición vascongada)" y "La dama de Amboto (tradición vasca)". Las leyendas intercaladas en "Mi última excursión a los Pirineos" serán igualmente reescritas como textos autónomos, como "La ondina del lago azul" y "La bella Toda y los doce jabalíes", e incluidas en las Obras Literarias (tomo V). Además de estas leyendas, GGA había escrito con anterioridad otros textos legendarios como La baronesa de Joux (1844), "La velada del helecho" (1849), y “La montaña maldita” (1851).

6 "La Peregrina" será el seudónimo utilizado por GGA en 1839 para firmar sus primeros poemas, publicados en el periódico gaditano La Aureola.

7 La nación experienciada como extensión geo-política comienza a conformarse en relatos como "Excursión a vueltabajo” de Cirilo Villaverde $(1838,1842)$.

8 Dice Heredia en su himno: "Tierra! claman: ansiosos miramos/ al confin del sereno horizonte/ y á lo lejos descúbrese un monte... Le conozco... Ojos tristes, llorad!/ Es el Pan... En su falda respiran/ el amigo mas fino $y$ constante,/ mis amigas preciosas, mi amante....Qué tesoros de amor tengo allí!" (Heredia, 1853, p. 156).

9 En el "Himno del desterrado" de Heredia la armonía natural es acallada con los "sonidos" de la esclavitud: "clamor del tirano insolente,/ del esclavo el gemir lastimoso,/ y el crujir del azote horroroso/ se oye solo en tus campos sonar" (1853, p. 158).

10 Alejandro de Humboldt en su Ensayo político sobre la isla de Cuba habla de la Sierra de Tarquino (Humboldt, 1827, p. 39), nombre que había sido fijado en 1569 en el mapamundi del geógrafo flamenco Gerardo Kremer Mercator y que será repetido, además, en la Carta de Vives (1835). Sin embargo, en la edición décimoséptima (1857) de Geografía física y política..., Felipe Poey argumenta: "Esta altura se llama vulgarmente Sierra Turquina, sinónimo de turquí ó azul á semejanza de las montañas azules de Jamaica, que por su distancia y elevacion aparecen de este color. Los que ignoran esta etimología han achacado al vulgo reminiscencias de la historia romana, Ilamándola de Tarquino (...) El mapa de Barcelona, copinado á D. José del Río, escribe Tarquino; pero Valdés, en la historia de la Habana, había dicho mucho antes Sierras Turquinas, y lo mismo dice el mapa de Salazar, anterior al de Barcelona" (Poey, 1857, pp. 43-44).

11 En la obra en cuestión, la protagonista vive en un hortus conclusus que el rey padre construye para ella como alternativa para ocultar su ceguera. Cuando la hija descubre su limitación y logra ver, tras la intervención de un médico, se entrega al exaltado reconocimiento de lo que antes no había podido percibir. El lugar natal adquiere, en este caso, una vitalidad insospechable ante su mirada adánica.

12 En la descripción que hace GGA de la imagen pictórica, los colores involucran movimientos, sonidos y olores, creando ilusiones perceptivas: "Aquel cielo, que hasta entónces sólo presentára colores, se fue diafanizando, esclareciendo, cobrando movilidad, por decirlo así (...) Las ligeras nubecillas (...) se extendieron libres y vaporosas por el azul brillante del cielo tórrido, cuyo calor fecundo parecía brotar del pincel (...) Los árboles, las plantas, las flores, se esmaltaban con la luz, se mecían casi -permítasenos la hipérbole-, como al suave soplo de los frescos aliseos, y tal era el poder de la ilusion, que se sentia aquella atmósfera impregnada de aromas, llena de susurros, encendida por los rayos del trópico" (Gómez de Avellaneda, 1861, pp. 148-149).

13 Como trasfondo del poema, la crítica (Pratt, 1992, pp. 193-194) ha hecho visibles las retóricas fundacionales de producción del paisaje americano por parte de una mirada totalizadora y falocéntrica (desde Humboldt, Andrés Bello, Heredia) que GGA revisa y pone en ridículo, al hacer visible el impulso utópico que mediatiza la recepción del paisaje americano.

14 Una imagen similar es recreada en la plegaria "A la Virgen". Psique y paisaje quedan homologados por la misma oposición interior/ exterior: "Este abismo de dolores/ Que con flores/ Disfraza tal vez la suerte;/ iVolcan que encierra la muerte,/ Coronado de verdores!" (Gómez de Avellaneda, 1869, p. 88).

15 Hay varias referencias al volcán o al fuego en la obra avellanedina, como si la autora se valiera de la creencia de los nativos americanos citada en Guatimozín, para quienes las erupciones volcánicas "eran anuncios de grandes calamidades" (Gómez de Avellaneda, 1853, p. 54); calamidades que evocan la historia colonial. En Sab la muerte de Camagüey se metaforiza como volcán en erupción -el cuerpo del cacique es arrojado desde la cumbre de una montaña y su sangre cubre y tiñe las tierras de Cubitas; a su vez un incendio reducirá a cenizas la morada de Martina, descendiente directa de la raza indígena en la novela. En El artista barquero, la heredad patriarcal también quedará reducida a cenizas, más tarde será reedificada para luego terminar finalmente destruida por el impulso utilitarista de sus nuevos dueños.

16 La preocupación en torno al sustento y viabilidad de la figura del artista en las nuevas condiciones de producción capitalitas ronda a Gómez de Avellaneda por estos años, como se lee en el artículo "Situación actual del artista", publicado en El album en 1860.

\section{BIBLIOGRAFÍA}

Alzate Cadavid, C. (2001). La Avellaneda en Cuba. Los espacios imaginarios de la historia literaria. Estudios. Revista de Investigaciones literarias y culturales, 17 , pp. 129-148.

Bauman, Z. (2003). De peregrino a turista, o una breve historia de la identidad. En Hall, S. y de Gay, P. (eds.), Cuestiones de identidad cultural. Buenos Aires: Amorrortu, pp. 40-68.
Betancourt, J. R. (1914). Himno en la coronación de la Avellaneda. En Miranda, A. (ed.). Gertrudis Gómez de Avellaneda. Obras. Miscelánea (vol. 6). La Habana: Imprenta de A. Miranda, pp. 506-508. 
Bosmeniel, T. (1844). Refutación al folleto intitulado Viage a la Habana. La Habana: Imprenta del Gobierno y Capitanía General.

Cros, E. (2010). El campo cultural de la segunda mitad del siglo XIX (Freud, Saussure, Poética, Pintura abstracta) y su articulación con la Historia [en línea]. [Fecha de consulta: 19 de octubre de 2014]. Disponible en: http://sociocritique.fr/spip.php?article46

Escoto, J. A. (1911). Gertrudis Gómez de Avellaneda. Cartas inéditas y documentos relativos a su vida en Cuba de 1859 a 1864. Matanzas: Imprenta La Pluma de Oro.

Espina y Capo, A. (1901). Estudio de climoterapia é higiene del enfermo en esta estación: Panticosa, Pirineos españoles. Madrid: Imprenta Asilo de Huérfanos del Sagrado Corazón de Jesús.

Ezama Gil, A. (2011). Los relatos de viaje de Gertrudis Gómez de Avellaneda. Anales de Literatura Española, 23, pp. 323-351.

Fornaris, J. (1914). A Gertrudis Gómez de Avellaneda. En Gómez de Avellaneda, G. Obras. Miscelánea (vol. 6). La Habana: Imprenta de A. Miranda, pp. 508-510.

Gómez de Avellaneda, G. (1841). Sab: novela original. Madrid: Imprenta Calle del Barco.

Gómez de Avellaneda, G. (1844/2008). Apuntes biográficos de la Señora Condesa de Merlin. En Santa Cruz y Montalvo, M. (Condesa de Merlin). Viaje a la Habana. Florida: Stockcero, pp. XXXI-XXXIV.

Gómez de Avellaneda, G. (1850). Poesias. Madrid: Imprenta de Delgrás Hermanos.

Gómez de Avellaneda, G. (1853). Guatimozín, último emperador de Méjico: novela histórica. México: Imprenta de Juan R. Navarro.

Gómez de Avellaneda, G. (1855). La hija del rey René: drama en un acto. Madrid: Imprenta de José Rodríguez.

Gómez de Avellaneda, G. (1860/1914). Mi última excursión por los Pirineos. En Miranda, A. (ed.). Obras. Miscelánea (vol. 6). La Habana: Imprenta de A. Miranda, pp. 7-47.

Gómez de Avellaneda, G. (1860/2005). Prólogo [a Poesías de Luisa Pérez de Zambrana]. En Montero, S. (ed.). La Avellaneda bajo sospecha. Letras Cubanas: La Habana, pp. 159-166.

Gómez de Avellaneda, G. (1861). El artista barquero ó los cuatro cinco de junio. Habana: Imprenta El Iris.

Gómez de Avellaneda, G. (1869). Obras literarias. Poesías líricas (tomo I). Madrid: Imprenta y estereotipia de M. Rivadeneyra.

Heredia, J. M. (1853). Poesias. Nueva York: Roe Lockwood \& Son.

Humboldt, A. de (1827). Ensayo político sobre el reino de la Nueva España. Paris: Jules Renouard librero. http://dx.doi. org/10.5962/bhl.title.38073 lanes, R. (1997). La esfericidad del papel. Gertrudis Gómez de Avellaneda, la condesa de Merlin y la literatura de viajes. Revista Iberoamericana, 178-179, pp. 209-218.

Palma, R. de. (1860/1914). A la coronación de la Sra. doña Gertrudis Gómez de Avellaneda. En Miranda, A. (ed.). Obras. Miscelánea (vol. 6). La Habana: Imprenta de A. Miranda, pp. 514-519.

Poey, F. (1857). Geografía física y política de la isla de Cuba (17ạ ed.). La Habana: Imprenta de la viuda de Barcina.

Pratt, M. L. (1992). Imperial Eyes: Travel Writing and Transculturales. London: Routledge.

Pratt, M. L. (1993). Las mujeres y el imaginario nacional en el siglo XIX. Revista de Crítica Literaria Latinoamericana, 38, pp. 51-62. http://dx.doi. org/10.2307/4530672

Pratt, M. L. (2003). La poética de la perversión. Poetisa inubicable devora a su maestro. No se sabe si se trata de aprendizaje o de venganza. En SchmidtWelle, F. (ed.). Ficciones y silencios fundacionales. Literaturas y culturas postcoloniales en América Latina, siglo XIX. Frankfurt am Main: Vervuert / Madrid: Iberoamericana, pp. 27-46.

Sarduy, S. (1982). Tu dulce nombre halagará mi oído. En Cabrera, R. M. y Zaldívar, G. B. (comps.). Homenaje a Gómez de Avellaneda. Memoria del Simposio en el centenario de su muerte. Miami: Universal. 